\begin{tabular}{|l|l|}
\hline & \\
&
\end{tabular}

\title{
Previdência social, trabalho e pessoa com deficiência
}

Social security, work and the disabled person

\section{Alano do Carmo \\ Macedo ${ }^{1}$ \\ orcid.org/0000-0002-3578-9553 \\ alanomacedo@yahoo.com.br}

Recebido em: 25 dez. 2019 Aprovado em: 04 mar. 2020. Publicado em: 30 out. 2020
Resumo: Este trabalho examina, a partir dos dados fornecidos pelo Instituto Nacional do Seguro Social, a aposentadoria do trabalhador com deficiência no contexto contemporâneo de contrarreformas governamentais no âmbito da seguridade social brasileira. A deficiência é analisada, aqui, como resultado de uma produção da sociabilidade regida sob a lógica do capital em um país de capitalismo periférico e dependente: o Brasil. Este é marcado, ainda, pela superexploração do trabalho, o que resulta na intensificação dos mecanismos de extração da mais-valia e de políticas sociais cada vez mais agudizadas pela focalização e seletividade no mitico estado de direito burguês. As taxas negativas são superiores às de concessão do benefício, tão afinadas ao esperado pela burguesia rentista que busca ampliar a mercantilização dos serviços sociais.

Palavras-chave: Trabalho. Previdência Social. Pessoa com deficiência.

Abstract: This work examines, based on data provided by the Brazilian National Institute of Social Security, the retirement of workers with disabilities in the contemporary context of government counter-reforms in the context of Brazilian social security. Disability is analyzed here as a result of a production of sociability governed by the logic of capital in a country of peripheral and dependent capitalism: Brazil. This is also marked by the overexploitation of labor, which results in the intensification of the mechanisms of surplus value extraction and of social policies increasingly exacerbated by the focus and selectivity in the mythical bourgeois state of law. The negative rates are higher than those for granting the benefit, so in tune with the expectations of the rentier bourgeoisie that it seeks to expand the commodification of social services.

Keywords: Work. Social Security. Disabled person.

\section{Introdução}

O benefício previdenciário que trata da aposentadoria da pessoa com deficiência, segurada do Regime Geral de Previdência Social (RGPS), tem suas bases legais na Constituição Federal de 1988 (CF/1988), parágrafo primeiro, artigo 201. Porém, só foi regulamentada 25 anos após tal previsão legal, por meio da Lei Complementar $n^{\circ}$ 142, de 8 de maio de 2013.

O benefício operacionalizado pelo Instituto Nacional do Seguro Social (INSS), para ser reconhecido, considera pessoa com deficiência aquela que tem impedimentos de longo prazo de natureza física, mental, intelectual ou sensorial, os quais, em interação com diversas barreiras, podem obstruir sua participação plena e efetiva na sociedade em igualdade de condições com as demais pessoas. Tudo isso, claro, está inscrito no complexo processo permeado por antagonismos tão caros à sociabilidade regida sob a lógica do capital que adquire dividas para superação das crises. Como consequência, ocorre o desmantelamento das políticas sociais, onde reside a justificativa para o ajuste fiscal.
Artigo está licenciado sob forma de uma licença Creative Commons Atribuição 4.0 Internacional. 
Compreendemos que os critérios cada vez mais restritivos de acesso não só a esse, mas a todos os benefícios previdenciários, mantêm estreita relação com a manutenção de um fundo público que continua sendo canalizado para a manutenção da ordem do capital, em uma lógica potencialmente perversa, decorrente dos mecanismos de mundialização. Isto pode ser constatado, por exemplo, com o papel das dívidas públicas a subtrair recursos do Estado em favor da esfera rentista. Em outras palavras: a retirada de direitos da classe trabalhadora ocorre com o intuito de atender aos interesses dominantes, o que justifica tal ação pela contenção dos gastos públicos.

Assim, estamos cientes que, apesar dos aparentes avanços em relação aos direitos dos trabalhadores com deficiência no Brasil - principalmente com a aprovação do Decreto Legislativo $n^{\circ}$ 186/2008 -, os fundamentos legais, as normativas institucionais e os instrumentos técnicos utilizados pelos profissionais convergem para a defesa dos interesses do capital. E este nega o direito previdenciário, em um contexto marcado pela austeridade fiscal adotada pelo governo brasileiro.

O interesse por tal investigação decorre de nossa atuação profissional enquanto assistente social do INSS, que integra o processo da avaliação médica e funcional da pessoa com deficiência segurada do RGPS. Nossa proposta de discussão para este trabalho divide-se em três momentos distintos, embora correlatos à dinâmica espaço-tempo.

Em um primeiro momento, analisaremos a deficiência como resultado de uma produção social da sociabilidade capitalista e não como algo relacionado exclusivamente à pessoa, com os genes, compreensões isoladas do processo saúde, doença e/ou deficiência. Em seguida, pautamos o processo de reconhecimento do conceito da deficiência da Organização das Nações Unidas (ONU) ratificado pelo Brasil e dos aspectos juridico-formais até chegarmos às regulações mais específicas no âmbito do INSS. Por fim, avaliaremos dados pertinentes à aposentadoria da pessoa com deficiência no Brasil e no Estado do Rio de Janeiro, além de algumas estatísticas/ informações que caracterizam a atuação do INSS.

A escolha pelo Estado do Rio de Janeiro ocorreu com o intuito de otimizar o acesso às informações, uma vez que nossa atuação profissional no INSS, neste momento, dá-se no referido local. Também pensamos tratar-se de uma amostra representativa do Brasil, considerando que o Rio possui sete Gerências Executivas² (GEX), sendo 99 Agências da Previdência Social (APS) vinculadas às GEX. Dessas, aproximadamente, $41 \%$ ofertam a avaliação médica e funcional para o trabalhador com deficiência quando do reconhecimento do direito para fins de aposentadoria.

Encaminhamos, com fundamento na Lei $n^{\circ}$ 12.527 de 18 de novembro de 2011 (Lei de Acesso à Informação), por meio do Sistema Eletrônico do Serviço de Informação ao Cidadão (e-SIC), solicitação de dados pertinentes à aposentadoria da pessoa com deficiência entre os anos de 2014 e 2017. A demanda reuniu quantitativos de requerimentos, indeferimentos e deferimentos para o periodo considerado. Ressaltamos que as informações referentes ao ano de 2014 não foram encaminhadas pelo INSS, pois não tiveram como ser depuradas devido a restrições na configuração dos sistemas operacionais (justifica-se a solicitação a partir de 2014 por ser ano de início da operacionalização do benefício).

Com os dados recebidos, ocorreu a interpretação e tratamento. As informações foram agrupadas em tópicos especificos e analisadas conforme os objetivos da pesquisa. Assim, ocorreram os processos de sistematização e produção textual, com observações teórico-empíricas e metodológicas.

Nessa direção, identificamos que, em tempos de financeirização da economia, ocorre uma pressão nas politicas sociais, especialmente sobre aquelas de seguridade, por situar o nicho dos produtos financeiros. Nesse sentido, as propostas de orientação neoliberal reverberam na transferência da proteção social do âmbito do Estado para o mercado, sendo a liberalização 
financeira o eixo norteador da privatização dos beneficios. No caso específico da previdência, as contrarreformas são parte de um amplo projeto do capital financeiro que vinculado à dinâmica mercadológica tem "jogado" para a classe trabalhadora um projeto de previdência privada com o desmantelamento da pública.

\section{Tese social, modelo biomédico e a Convenção da ONU: a produção social da deficiência em debate}

A narrativa social pauta as diferenças nas funções e nas estruturas do corpo como demonstrações do universo diversificado que é o corpo humano. Assim, enfatiza a organização da sociedade na perspectiva da possibilidade de enfrentamento da deficiência como uma questão pública, sem estar restrita à esfera privada e aos cuidados familiares. Para Diniz (2012), ela pode ser interpretada como o resultado do ordenamento político e econômico capitalista, "que pressupunha um tipo ideal de sujeito produtivo [...] a deficiência [...] decorria dos arranjos sociais opressivos às pessoas com lesão [...] sistemas sociais opressivos levavam pessoas com lesões a experimentarem a deficiência" (DINIZ, 2012, p. 24).

No pensamento ocidental, por um longo período, o corpo com diferenças e marcas era entendido como uma espécie de evidência mística - fosse pela ira ou pelo milagre divino. Porém, com o advento da narrativa biomédica sobre os aspectos relacionados ao corpo, o discurso sobre o extraordinário pelo mistério religioso foi perdendo ênfase, transformando-se numa narrativa cultural.

Com isso, a perspectiva biomédica adquiriu solidez para discorrer sobre as patologias e as enfermidades. Dessa forma, os corpos ganharam status de normais, anormais, monstruosos ou deficientes.

Nessa concepção, "a deficiência é a lesão no corpo, adquirida por meio de uma doença ou como consequência dessa. Decorre da deficiência uma excepcional incapacidade física, ao passo que tal condição de saúde leva os individuos a uma série de desvantagens sociais", como esclarece França (2014). Para ele, ademais, tal modelo pauta-se por uma ideologia normalizadora a consistir "na crença de que há um parâmetro normal que deve ser percebido e almejado pelos indivíduos e populações. Aqueles que se distanciam dessa referência devem sofrer ações interventoras para regularizar a situação ou, ao menos, reduzir o desvio" (FRANÇA, 2014, p. 8).

No Brasil, um importante avanço na abordagem da pessoa deficiência foi, por exemplo, o Censo de 2000, que introduziu aspectos específicos a romper com a perspectiva meramente patológica, embora incipiente. A pesquisa do Instituto Brasileiro de Geografia e Estatística (IBGE), no ano 2000 , apresentou novos elementos ao pautar os graus de dificuldades enfrentadas diariamente pelas pessoas com lesões, sejam elas relacionadas às habilidades de visão, audição ou locomoção.

Assim, em relação aos censos anteriores, percebemos uma mudança de paradigma. Os dados estatísticos do IBGE (2012) revelam que no ano 2000 14,5\% da população possuía alguma deficiência. Já em 2010, o índice sobe para 23,9\%, equivalente a pouco mais de 45 milhões de brasileiros.

Na contemporaneidade, ainda que com os tensionamentos do modelo biomédico (tão caro aos liberais por individualizar a pessoa com deficiência), a tese social, na contramão, adquire centralidade com foco nos direitos humanos dos sujeitos com deficiência. Assim, a doença e/ou deficiência, não estaria mais centrada na pessoa, mas na sociedade.

Esta, por sua vez, tem profundas dificuldades de lidar com as diferenças, com qualquer indivíduo que destoe de padrões estabelecidos pelo sistema metabólico do capital. Nesse cenário, mediante ampla discussão, na qual as pessoas com deficiência participaram ativamente do debate, emergiu a "Convenção Sobre os Direitos das Pessoas com Deficiência", adotada pela ONU em 13 de dezembro de 2006, de acordo com a Resolução 61/106 da Assembleia Geral. Ela, porém, entrou em vigor apenas em 3 de maio de 2008. No Brasil, esta convenção foi aprovada pelo Congresso Nacional, por meio do Decreto Legislativo 186/2008.

A Convenção aponta um conceito a partir de elementos que contribuem para desvendar concepções mitificadas, pois as tradicionais centram suas análises em conceitos clínicos, referendando toda 
e qualquer responsabilidade do indivíduo quanto à superação ou não das barreiras cotidianas em interação com o ambiente. Esta última concepção, conservadora desde a gênese, vai de encontro como conceito de pessoa com deficiência na referida norma, uma vez que o documento sinaliza para o Estado e a sociedade como responsáveis pelas barreiras em suas mais diversas expressões.

Assim, partindo do pressuposto que, em maior ou menor grau, todos os seres humanos possuem algum tipo de limitação, seja de ordem física, mental, psicológica, entre outras, podemos depreender que não seria, portanto, a limitação que caracterizaria a deficiência em si, mas as barreiras impostas pela sociedade. Como esclarece Fonseca:

A eliminação de barreiras arquitetônicas assegura o direito de ir e vir para as pessoas com deficiências físicas; a criação de meios alternativos de comunicação garante o direito de livre expressão para os surdos e cegos; os métodos de educação especial viabilizam o acesso ao conhecimento para qualquer pessoa com deficiência, mental ou sensorial. Quando essas medidas não são adotadas, excluem-se as pessoas com tais impedimentos, pondo-se a nu a incapacidade social de criar caminhos de acesso à realização plena dos direitos humanos. Quer-se, assim, transpor a ideia de que a responsabilidade pela exclusão da pessoa com deficiência se deve a ela ou sua familia, para que se compreenda que a sociedade também deve responsabilizar-se por oferecer instrumentos institucionais e tecnológicos para se abrirem as perspectivas de acolhimento e emancipação de todos (FONSECA, 2008, p. 06).

Não devemos, naturalmente, negar os fatores biológicos, mas eles devem ser contextualizados levando em consideração as barreiras cotidianas, a exemplo das arquitetônicas e/ou atitudinais. Compreendemos, nesse sentido, que estamos diante de uma percepção que apresenta uma nova perspectiva, principalmente ao elencar o meio ambiente social e econômico como elementos agravantes ou mesmo geradores de deficiência.

Ora, na esfera social, o desenvolvimento das forças produtivas resulta na reificação e alienação generalizada das relações humanas. Isso ocorre à proporção que o trabalhador é alienado dos mecanismos de produção e dos produtos do seu trabalho, ou seja, do processo produtivo em sua totalidade. Nesse contexto, está localizado, ou mes- mo reduzido, a um papel complementar junto de uma máquina que o consome física e mentalmente.

Ainda que goze de um suposto "tempo livre", a alienação, ainda assim, o consome pelo intenso processo de captura da subjetividade, ao ser envolvido pela comercialização do lazer por meio dos diversos mecanismos de comunicação de massa. Em outras palavras, é exercido sobre ele uma espécie de domínio do ser social, tanto no trabalho como fora dele, como se ocorresse a perda de controle humano sobre as próprias atividades na tessitura da vida social (MANDEL, 1981).

Nesse sentido, como o propósito capitalista é sempre manter a acumulação, ou seja, o lucro, essa produção termina não tendo um cuidado especial com a condição de saúde dos trabalhadores. Marx já sinalizava os reflexos da extenuante jornada de trabalho inglesa, associada às péssimas condições laborativas, que não poupavam nem as crianças, conforme relatórios médicos:

O sr. Charles Parsons, até pouco tempo atrás
house surgeon [médico cirurgião] desse mesmo
hospital, escreve numa carta ao comissário
Longe, entre outras coisas: 'Posso falar apenas
com base em minhas observações pessoais, e
não estatisticamente, mas não hesito em afirmar
que minha indignação cresceu cada vez mais ao
olhar para essas pobres crianças, cuja saúde foi
sacrificada para satisfazer a cupidez de seus pais
e de seus empregadores' (MARX, 1988, p. 407).

Com isso, é possivel perceber a estarrecedora relação entre as intensas jornadas laborativas e as péssimas condições de trabalho que reverberam na saúde dos trabalhadores à época (crianças, jovens e adultos). Marx (1988) revela que tal situação não está restrita ao cenário fabril inglês, mas se estende a outros países, a exemplo da Escócia, estando presente também em uma diversidade de atividades. Conforme esclarece:

A manufatura de palitos de fósforo data de 1833, quando se inventou o método de aplicação do fósforo no palito. Desde 1845, essa manufatura desenvolveu-se rapidamente na Inglaterra e, depois de se espalhar pelas partes densamente povoadas de Londres, expandiu-se principalmente para Manchester, Birmingham, Liverpool, Bristol, Norwich, Newcastle e Glasgow, levando consigo o tétano, que, já em 1845, um médico de Viena detectara como doença peculiar aos fosforeiros. A metade dos trabalhadores são crianças 
menores de 13 e jovens menores de 18 anos. Em virtude de sua insalubridade e repugnância, a manufatura é tão mal afamada que apenas a parte mais miserável da classe trabalhadora, como viúvas semifamélicas etc., entregam seus filhos a essas fábricas: 'crianças esfarrapadas, semifamélicas, totalmente desamparadas e sem instrução'. Das testemunhas ouvidas pelo comissário White (1863), 270 eram menores de 18 anos, 40 eram menores de 10 anos, 10 tinham apenas 8 anos e 5 apenas 6 anos de idade. A jornada de trabalho variava entre 12 , 14 e 15 horas, com trabalho noturno e horários irregulares de refeições, normalmente realizadas no próprio local de trabalho, empestado por fósforo. Nessa manufatura, Dante veria superadas suas fantasias mais cruéis sobre 0 inferno (MARX, 1988, p. 408).

Tais aspectos referendam não só atese defendida aqui a respeito da lógica produtiva capitalista, também geradora de deficiência, o que amplia a percepção para além de uma gênese intrinsecamente relacionada ao aspecto congênito. Isto não desqualifica, porém, a discussão levantada no presente trabalho sobre as barreiras em suas mais diversas expressões presentes na sociabilidade do capital, desvendando um perverso sistema que tenta se eximir da responsabilidade por algo que é também gerador.

Tais análises não são deslocadas do contexto de fetichização das relações sociais sob a égide do capital, com a radicalização da alienação que intensifica a superexploração do trabalhador para manutenção das taxas de lucro na agudização da crise capitalista. Criando um cenário que torna as desigualdades sociais cada vez mais opacas no mundo atual, elas aumentam consideravelmente o desmantelamento do sistema de proteção social como mecanismo que fortalece a mercantilização dos serviços sociais tão caro aos liberais.

\section{Aspectos normativo-legais}

O Brasil, por meio do Decreto n. 6.949, de 25 de agosto de 2009, promulgou a Convenção Internacional sobre os Direitos das Pessoas com Deficiência (doravante, a Convenção) e seu protocolo facultativo, assinados em Nova York em 30 de março de 2007, em Assembleia Geral da ONU e aprovado segundo o procedimento estabelecido no $\$ 3^{\circ}$ do Art. $5^{\circ}$ da CF/1988 pelo Decreto Legislativo n 186 , de 9 de julho de 2008. A referida Convenção foi, portanto, incorporada ao texto constitucional.

A Convenção da ONU sobre os Direitos das Pessoas com Deficiência endossa um conceito que rompe com as concepções que fundamentam a perspectiva biomédica. ${ }^{3}$ Assim, o sujeito com deficiência é compreendido em interação com as diversas barreiras cotidianas: ante tal visão, o problema não é individual, mas da sociedade que não está preparada para atender demandas especíicas. Porém, é imperativo perceber as inflexões dessas análises no bojo da sociabilidade do capital, como entendido por Hillesheim:

\begin{abstract}
No pensamento burguês, o direito é concebido como um pressuposto para a subsistência da própria sociedade, e todas as relações sociais devem sujeitar-se às regras juridicamente definidas. Tal perspectiva naturaliza o fenômeno jurídico e desconsidera sua historicidade. Essa forma a-histórica de conceber o direito coloca-o no campo das ideologias com a finalidade de conquistar o consenso em torno da viabilidade e naturalização na sociabilidade do capital, negando, ao fim e ao cabo, a existência da diferenciação de classes e os antagonismos dela decorrentes (HILLESHEIM, 2015, p. 135).
\end{abstract}

Desde a CF/1988, em seu Art. 24, já era possivel identificar a responsabilidade do Estado para legislar sobre a proteção social das pessoas com deficiência. No caso da política previdenciária pública, entretanto, somente por meio da Emenda Constitucional $n^{\circ}$ 47/2005 ocorrera a previsão de aposentadoria para trabalhadores com deficiência baseado em critérios especificos, sendo regulamentada por meio da LC 142/2013. O Decreto n 8.145/2013, a seu turno, alterou o Regulamento da Previdência Social (RPS), aprovado pelo Decreto n 3.048/1999, a fim de dispor sobre o benefício ao segurado com deficiência. Dessa forma, ficou estabelecido o seguinte:

A concessão da aposentadoria por tempo de contribuição ou por idade ao segurado que tenha reconhecido, em avaliação médica e funcional realizada por perícia própria do INSS, grau de deficiência leve, moderada ou grave,

\footnotetext{
3 A perspectiva biomédica, ressalte-se, percebe a deficiência como um problema a ser solucionado pela medicina no âmbito das estruturas e funções do corpo.
} 
está condicionada à comprovação da condição de pessoa com deficiência na data da entrada do requerimento ou na data da implementação dos requisitos para o benefício.

Nos parágrafos primeiro e segundo do Art. $2^{\circ}$ da Portaria Interministerial AGU/MPS/SEDH/MP n 01 de 27/01/2014, é determinado que(grifo nosso):

$\S 1^{\circ} \mathrm{A}$ avaliação funcional indicada no caput será realizada com base no conceito de funcionalidade disposto na Classificação Internacional de Funcionalidade, Incapacidade e Saúde - CIF, da Organização Mundial de Saúde, e mediante a aplicação do Índice de Funcionalidade Brasileiro Aplicado para Fins de Aposentadoria - IFBrA, conforme o instrumento anexo a esta Portaria.

$\S 2^{\circ} \mathrm{A}$ avaliação médica e funcional, disposta no caput, será realizada pela perícia própria do INSS, a qual engloba a perícia médica e o serviço social, integrantes do seu quadro de servidores públicos.

O instrumento de avaliação do trabalhador com deficiência foi pautado a partir do Índice de Funcionalidade Brasileiro (IF-Br) ${ }^{4}$, elaborado pelo Instituto de Estudos do Trabalho e Sociedade (IETS), em parceria com a Secretaria de Direitos Humanos da Presidência da República e apoio da Universidade Federal do Rio de Janeiro (UFRJ), definindo a funcionalidade como eixo central. Este instrumento foi adaptado às exigências da LC 142/2013 e passou a ser denominado IF-BrA.

Ao ter seu direito reconhecido, o sujeito com deficiência pode continuar exercendo a atividade laborativa habitual sem que o beneficio seja cancelado, como seria o caso da aposentadoria por invalidez ou do auxílio-doença. Com relação aos requisitos, no caso do benefício por idade deve-se comprovar um tempo mínimo de 15 anos de contribuição como trabalhador com deficiência por meio da avaliação prevista na LC 142/2013.

Associado a isso, tem-se a exigência da idade mínima de 60 anos para homens e de 55 anos para mulheres, mas independe do grau de defi- ciência. Periodos de contribuição sem deficiência e com deficiência podem ser somados, sendo no caso daquele primeiro feita a devida conversão, nos termos da referida LC. Para o benefício por tempo de contribuição, a partir da classificação da deficiência, homens e mulheres deverão preencher requisito minimo, conforme quadro abaixo.

Oportuno registrar que a EC 103/2019 que trata da "Nova Previdência" manteve os requisitos para acesso aos benefícios nos termos da LC 142/2013, inclusive quanto aos critérios de cálculo do valor destes.

Quadro 1 - Relação entre tempo de contribuição e classificação da deficiência

\begin{tabular}{llll}
\hline & Leve & Moderada & Grave \\
\hline Homem & 33 anos & 29 anos & 25 anos \\
Mulher & 28 anos & 24 anos & 20 anos \\
\hline
\end{tabular}

Fonte: INSS. Elaboração própria.

Para o instrumental de avaliação médica e funcional, foram selecionadas categorias do componente Atividade e Participação da Classificação Internacional de Funcionalidade, Incapacidade e Saúde (CIF). Isto resultou na estruturação do escopo com 41 atividades divididas em sete domínios, a saber: sensorial; comunicação; mobilidade; cuidados pessoais; vida doméstica; educação, trabalho e vida econômica; socialização e vida comunitária.

A pontuação do IF-BrA tem como base o modelo de dependência da Medida de Independência Funcional (MIF). ${ }^{5}$ No entanto, não se utilizam os sete niveis de gradação originais, mas sim quatro destes, com o objetivo de facilitar a operacionalização do instrumento. Nesse processo, conforme detalhado no quadro abaixo, tem-se os seguintes valores: 25, 50, 75 e 100 (quanto menor o valor de classificação, maior é o nivel de dependência em relação à atividade realizada).

\footnotetext{
4 Na primeira fase do desenvolvimento do IF-Br, indicadores socioeconômicos de pesquisas do IBGE foram analisados. Também foram realizados grupos focais compostos por pessoas com deficiência, com o objetivo de compreender aspectos pertinentes à funcionalidade para essas pessoas. No segundo momento, o instrumento foi desenvolvido levando-se em conta os resultados da primeira etapa e a opinião de especialistas da área. Na conclusão do processo, 41 atividades representando sete domínios da funcionalidade foram selecionadas (FRANZOI et al., 2013).

5 Tem como objetivo primordial "avaliar de forma quantitativa a carga de cuidados demandada por uma pessoa para a realização de uma série de tarefas motoras e cognitivas de vida diária. Cada uma dessas atividades é avaliada e recebe uma pontuação que parte de 1 (dependência total) a 7 (independência completa) (RIBERTO et al., 2004).
} 
Quadro 2 - Parâmetros para qualificação das atividades nos domínios

\begin{tabular}{|c|c|}
\hline PONTUAÇÃO & DESCRIÇÃO \\
\hline 25 & $\begin{array}{l}\text { Não realiza a atividade ou é to- } \\
\text { talmente dependente de tercei- } \\
\text { ros para realizá-la. Não participa } \\
\text { de nenhuma etapa da atividade. }\end{array}$ \\
\hline 50 & $\begin{array}{l}\text { Realiza a atividade com o auxilio } \\
\text { de terceiros. O indivíduo partici- } \\
\text { pa de alguma etapa da ativida- } \\
\text { de. Inclui preparo e supervisão. }\end{array}$ \\
\hline 75 & $\begin{array}{l}\text { Realiza a atividade de forma adap- } \\
\text { tada, sendo necessário algum tipo } \\
\text { de modificação, ou realiza a ativi- } \\
\text { dade de forma diferente da habi- } \\
\text { tual ou ainda mais lentamente. }\end{array}$ \\
\hline 100 & $\begin{array}{l}\text { Realiza a atividade de forma inde- } \\
\text { pendente, sem nenhum tipo de } \\
\text { adaptação ou modificação, na ve- } \\
\text { locidade habitual e em segurança. }\end{array}$ \\
\hline
\end{tabular}

Fonte: Brasil, 2016

No processo de gradação da deficiência, a pontuação total mínima é de 2.050 e a máxima pode chegar a 8.200, o que depende da qualificação que cada avaliador atribui nas 41 atividades, multiplicadas por dois (número de profissionais responsáveis envolvidos). A partir da soma das duas avaliações, tem-se o total de pontos que expressa a classificação da deficiência. Para tanto, conforme quadro abaixo, são estabelecidas referências:
Quadro 3- Parâmetros para classificação da deficiência

\begin{tabular}{lll}
\hline $\mathbf{5} 5.739$ & $\mathbf{2 5 . 7 4 0}$ e $6 . \mathbf{3 5 4} \leq$ & $\mathbf{2 6 . 3 5 5}$ e $7.584 \leq$ \\
\hline GRAVE & MODERADA & LEVE \\
\hline
\end{tabular}

Fonte: INSS. Elaboração própria.

Os trabalhadores que obtiverem pontuações igual ou acima de 7.585 não vão ter o direito reconhecido. Isso porque esses valores são considerados insuficientes para acesso ao benefício. A avaliação vai fixar, também, a data provável do início da deficiência, bem como registrar possiveis variações no grau ao longo do tempo, e estabelecer a duração de respectivos periodos em cada grau, quando for o caso, sendo tal procedimento atribuido ao perito médico.

Na última etapa, quando pertinente, ocorre a aplicação do método linguístico fuzzy. Nessa situação, utilizam-se três condições para cada grupo de sujeitos que podem apresentar um maior comprometimento em relação ao impedimento (auditivo; intelectual-cognitivo e/ou mental; motor; e visual): 1) Determinação dos domínios que terão mais peso para cada grupo de funcionalidade; 2) Definição de questões emblemáticas; e 3) Disponibilidade do auxílio de terceiros.

No Quadro 4, apontam-se as distinções feitas entre os domínios e as perguntas emblemáticas para cada tipo de deficiência (cita-se apenas uma questão exemplificativa). No caso de resposta afirmativa para alguma das questões emblemáticas, nos domínios apontados como relevantes para aquela deficiência, todas as atividades assumem a menor pontuação ali encontrada, alterando a nota conclusiva anterior à aplicação do fuzzy.

Quadro 4 - Condições do método linguístico fuzzy.

\begin{tabular}{lllll}
\hline & Auditiva & $\begin{array}{l}\text { Intelectual/ } \\
\text { Cognitiva/Mental }\end{array}$ & Motora & Visual \\
\hline Domínios & $\begin{array}{l}\text { Comunicação/ } \\
\text { Socialização }\end{array}$ & $\begin{array}{l}\text { Vida Doméstica/ } \\
\text { Socialização }\end{array}$ & $\begin{array}{l}\text { Mobilidade/Cuida- } \\
\text { dos Pessoais }\end{array}$ & $\begin{array}{l}\text { Mobilidade/ } \\
\text { Vida Doméstica }\end{array}$ \\
$\begin{array}{l}\text { Questão Emblemática } \\
\text { (apenas uma das três) }\end{array}$ & $\begin{array}{l}\text { A surdez ocorreu } \\
\text { antes dos 6 anos }\end{array}$ & $\begin{array}{l}\text { Não pode ficar sozi- } \\
\text { nho em segurança }\end{array}$ & $\begin{array}{l}\text { Desloca-se ex- } \\
\text { clusivamente em } \\
\text { cadeiras de rodas }\end{array}$ & $\begin{array}{l}\text { A pessoa já não } \\
\text { enxergava ao } \\
\text { nascer }\end{array}$ \\
\hline
\end{tabular}

Fonte: INSS. Elaboração própria. 
Cada uma das 41 atividades é pontuada separadamente, sendo a classificação de cada domínio atribuida à média das atividades. Por conseguinte, a pontuação total é a média dos 7 domínios do instrumental. Desse modo, tem-se o resultado após aplicação por perito médico e assistente social. Igualmente, o parecer final leva em consideração a aplicação do modelo fuzzy, responsável pela correção da pontuação, quando aplicado.

Registre-se a fragilidade do instrumental que não pontua diretamente os fatores ambientais/ contextuais, além de abordagens constrangedoras em alguns domínios, a exemplo da atividade "relacionamentos intimos" e outras que contribuem para retomada da perspectiva biomédica como "movimentos finos da mão", "lavar-se", "vestir-se", "comer", "beber".

Dessa forma, é possivel depreender que o instrumental pode contribuir para avaliações que não conseguem mensurar contextos prejudiciais ao desempenho, donde prevalecem as determinações biológicas. Disso resulta a urgência do debate coletivo e a revisão desse mecanismo avaliativo: é necessário pautar e considerar de forma mais objetiva na avaliação os aspectos sociais dos trabalhadores com deficiência, principalmente a partir das particularidades das condições de vida e trabalho e sua intrinseca correlação com a política de proteção social no país e seus determinantes históricos.

Para tanto, é preciso considerar os seguintes aspectos: a singular história de vida dos sujeitos; os produtos e tecnologias disponiveis na sociedade; as condições de moradia e habitação, acesso ao local de trabalho; relacionamentos e apoio nas esferas familiar e comunitária; observar as relações sociais estabelecidas; as estigmatizadas atitudes preconceituosas e discriminatórias, por vezes, estabelecidas na familia e comunidade, que associam toda e qualquer deficiência à incipiente ou mesmo ausência de intelecto.

Em outras palavras, torna-se imprescindivel notar e pontuar as barreiras presentes na dimensão dos fatores ambientais, as limitações para desempenhar atividades e os aspectos que, notadamente, restringem a participação social.
A linguagem dos dados estatísticos no Brasil com ênfase no Estado do Rio de Janeiro

Dada a vasta capilaridade de ação por meio das Agências da Previdência Social (APS) por questões administrativas, o INSS está dividido em cinco superintendências regionais, quais sejam: Norte/Centro-Oeste, Nordeste, Sudeste I, Sudeste II e Sul. Estas são responsáveis por gerenciar as unidades nos Estados e no Distrito Federal a partir das Gerências Executivas (GEX) e as APS vinculadas a elas, conforme quadro abaixo.

Quadro 5 - Quantitativos (Superintendência/ Estados/Gerências Executivas)

\begin{tabular}{lll}
\hline Superintendência & $\begin{array}{l}\text { Estado (mais o } \\
\text { Distrito Federal) }\end{array}$ & Gerências \\
\hline Norte/ & AC, AM, AP, DF, & \\
Centro-Oeste & $\begin{array}{l}\text { GO, MT, MS, PA, } \\
\text { RO, RR, TO }\end{array}$ & 17 \\
Nordeste & AL, BA, CE, MA, & 23 \\
Sudeste I & PE, PB, PI, RN, SE & \\
Sudeste II & SP & 23 \\
Sul & ES, MG, RJ & 22 \\
Total & PR, RS, SC & 19 \\
\hline
\end{tabular}

Fonte: INSS. Elaboração própria.

Os dados obtidos do INSS, por meio da Lei 12.527/2011, são pertinentes ao período compreendido entre 2015 e 2017. Também fora solicitado acesso às estatísticas desde a operacionalização do benefício no ano de 2014. No entanto, foi-nos informado que a depuração dos sistemas operacionais de dados relativos ao benefício somente fora adequada para extração do Sistema Único de Beneficios (SUB) posterior ao início da concessão das aposentadorias da LC 142/2013, o que justifica a ausência dos elementos a partir de 2014.

A superintendência do INSS na região Nordeste possui as seguintes GEX a ela vinculadas: Aracaju. Barreiras, Campina Grande, Caruaru, Feira de Santana, Fortaleza, Garanhuns, Imperatriz, Itabuna, João Pessoa, Juazeiro, Juazeiro do Norte, Maceió, 
Mossoró, Natal, Petrolina, Recife, Salvador, Santo Antônio de Jesus, São Luís, Sobral, Teresina e Vitória da Conquista.

Os dados relativos a essas unidades gerenciais revelam que a Gerência Executiva Recife possui a maior demanda de requerimentos, embora as unidades de atendimento vinculadas às Gerências Executivas em Fortaleza e em Salvador apresentem volume bem próximo daqueles em Recife. Já a Gerência Executiva Barreiras apresentou o menor quantitativo para o periodo considerado, quando comparado às outras unidades administrativas do INSS na região Nordeste, onde, também, identificou-se que $100 \%$ dos benefícios protocolados na referida unidade foram indeferidos.

Nas demais Gerências Executivas, observou-se que o percentual de benefícios concedidos entre os anos de 2015 e 2017 variou de $4 \%$ a 20\%, sendo estas taxas identificadas, respectivamente, nas unidades administrativas em Itabuna e Fortaleza. Assim, a capital cearense figura uma das maiores demandas da superintendência regional do Nordeste e com o melhor índice de concessão do benefício para o período analisado.

Na superintendência do INSS responsável pelas regiões Norte e Centro-Oeste, estão as seguintes unidades gerenciais: Anápolis, Belém, Boa Vista, Campo Grande, Cuiabá, Distrito Federal, Dourados, Goiânia, Macapá, Marabá, Manaus, Palmas, Porto Velho, Rio Branco, Santarém, Sinop e Tefé. Os dados dessas GEX revelam que a Gerência Executiva no Distrito Federal é responsável pela maior demanda dentre as unidades vinculadas à superintendência regional Norte/ Centro-Oeste e aquela com menor quantidade de requerimentos pertence à Gerência Executiva Tefé, tendo nesta última o pior indice de indeferimento do benefício com 100\% dos pedidos negados. Com relação às taxas de concessão nas demais unidades do INSS para o período considerado, identificou-se que Marabá registrou taxa inferior a $2 \%$, enquanto a unidade gerencial em Goiânia apresentou o melhor índice de deferimento com o percentual aproximado de $15 \%$.

Já as unidades vinculadas à superintendência do INSS na região Sudeste I (todas no Estado de
São Paulo) são: Araçatuba, Araraquara, Bauru, Campinas, Guarulhos, Jundiai, Marilia, Osasco, Piracicaba, Presidente Prudente, Ribeirão Preto, Santo André, Santos, São Bernardo do Campo, São João da Boa Vista, São José do Rio Preto, São José dos Campos, São Paulo-Centro, São Paulo-Norte, São Paulo-Sul, São Paulo-Leste, Sorocaba e Taubaté.

Para este cenário, os dados apresentados apontam que a demanda mais expressiva, em termos numéricos, está na Gerência Executiva São Paulo-Sul e aquela com menor quantitativo de requerimentos protocolados é a unidade administrativa do INSS em Presidente Prudente. No período considerado, a menor taxa de concessão do benefício ocorreu em Guarulhos, com aproximadamente $7.5 \%$ dos pedidos deferidos. Já na Gerência Executiva São Bernardo do Campo, com a segunda maior demanda de benefícios requeridos do Estado de São Paulo, fora registrado aproximadamente indice de $25 \%$ de pareceres favoráveis.

Na Superintendência Sudeste II, a seu turno, temos: Barbacena, Belo Horizonte, Campos dos Goytacazes, Contagem, Diamantina, Divinópolis, Duque de Caxias, Juiz de Fora, Montes Claros, Niterói, Ouro Preto, Petrópolis, Poços de Caldas, Rio de Janeiro-Centro, Rio de Janeiro-Norte, Teófilo Otoni, Uberaba, Uberlândia, Varginha, Vitória e Volta Redonda. Para esta realidade, identificamos que a demanda mais elevada do beneficio está concentrada na Gerência Executiva Rio de Janeiro-Centro e a menor na unidade administrativa do INSS em Diamantina (MG). Com relação ao quantitativo de benefícios concedidos, o melhor indice em termos de pareceres favoráveis é da Rio de Janeiro-Centro, com dado aproximado de $22 \%$, enquanto a de Teófilo Otoni (MG) tem o menor percentual de concessão, em torno de 5\%.

Na superintendência da região Sul, temos as seguintes unidades gerenciais: Blumenau, Canoas, Cascavel, Chapecó, Caxias do Sul, Curitiba, Criciúma, Florianópolis, ljuí, Joinville, Londrina, Maringá, Novo Hamburgo, Passo Fundo, Pelotas, Ponta Grossa, Porto Alegre, Santa Maria e Uruguaiana. Os dados revelam que a GEX com 
maior demanda é aquela localizada na capital paranaense. A unidade gerencial do INSS com um menor número de requerimentos protocolados é, por sua vez, a situada na cidade de Uruguaiana e que também apresenta o mais baixo índice de concessão, com apenas 7\%, enquanto a Gerência Executiva Caxias do Sul expressa a melhor taxa dessa superintendência: $25 \%$ de deferimentos.

Por nossa atuação profissional ser exercida, atualmente, no Estado do Rio de Janeiro, buscamos elementos para refletirmos sobre o cotidiano de trabalho, a partir de dados objetivos mais especificos. Assim, fora possivel identificar que, de um total de 12.378 requerimentos para o período entre os anos de 2015 a 2017, a Gerência Executiva Rio de Janeiro-Centro (GEXRJC) concentrou quase 15\% (1.792) da análise total desses protocolos iniciais, sendo a mais expressiva dentre as GEX vinculadas à Superintendência Regional Sudeste II (SR II), seguida das demandas registradas nas unidades gerenciais em Belo Horizonte e Vitória.

Oportuno registrar que, dentre as três capitais que compõem esta unidade administrativa do INSS, a cidade do Rio de Janeiro é a mais populosa, com, aproximadamente, 6,3 milhões de habitantes. Destes, 25\% têm algum tipo de deficiência ou algum tipo de mobilidade reduzida, seja motora ou intelectual, segundo o último Censo em 2010, o que pode explicar a expressividade da demanda pelo benefício em relação às outras duas (IBGE, 2012).

O Rio possui sete GEX, sendo duas localizadas na capital fluminense (Centro e Norte) e as demais nas cidades de Campos dos Goytacazes, Duque de Caxias, Niterói, Petrópolis e Volta Redonda. Ao depurarmos as estatísticas para o periodo em análise, discriminando as informações a cada ano, percebemos que a demanda direcionada à GEXRJC sempre fora superior àquela identificada para as demais. Isto talvez possa ser justificado pela localização das APS a ela vinculadas, pois estão situadas, em sua maioria, nas proximidades dos centros e instituições empresariais as quais, por vezes, cumprem a legislação federal que prevê cotas para trabalhadores com deficiência.

Evidenciamos que do total de 5.216 requerimentos para o Estado, aproximadamente 32\%
(1.792) destes foram protocolados na GEXRJC. Nessa unidade administrativa foram requeridos 1.792 beneficios para o periodo de 2015 a 2017. Destes, 395 foram concedidos; outros 773 indeferidos e 624 foram negados pela instituição devido ao não cumprimento de exigência administrativa (como, por exemplo, ausência de documentação comprobatória para períodos declarados que não constavam nos Cadastro Nacional de Informações Sociais - CNIS, e também não comprovados por outros documentos junto ao INSS).

A diversidade de compreensões sobre deficiência e o modo como estas reverberam no reconhecimento do direito, ressalte-se, podem ser evidenciados em cada uma das sete unidades gerenciais do INSS no Estado do Rio de Janeiro, utilizando informações de benefícios que passaram por todas as etapas de análise, desde a habilitação administrativa até as avaliações médica e social.

Na Gerência Executiva Campos dos Goytacazes, por exemplo, 29\% dos requerimentos analisados no ano de 2015 tiveram parecer favorável à concessão do benefício, enquanto $71 \%$ foram negados. Em 2016, apesar do aumento na demanda, houve redução na taxa de deferimento, que ficou em $10 \%$, ou seja, $90 \%$ dos trabalhadores não tiveram o direito reconhecido. Já em 2017, ocorreu um crescimento de protocolos iniciais em relação aos dois anos anteriores, porém somente $16 \%$ foram concedidos e a expressiva maioria foi negada com taxa de $84 \%$ de pedidos indeferidos.

No caso da Gerência Executiva Duque de Caxias, em 2015 apenas 19\% foram deferidos. Assim, ficaram sem acesso à aposentadoria $81 \%$ dos trabalhadores. No ano seguinte, a demanda pelo beneficio aumentou, mas a taxa de concessão diminuiu para $8 \%$, ou seja, não tiveram o direito reconhecido um total de 92\% de pessoas com deficiência. Em 2017, os indices se mantiveram próximos aos do ano anterior, com a inexpressiva taxa de 10\% de segurados com pedidos deferidos. Desse modo, 90\% dos trabalhadores não tiveram o direito reconhecido.

$\mathrm{Na}$ Gerência Executiva Niterói, identificamos, a partir dos dados fornecidos pelo INSS no ano de 2015, índice de concessão de 36\%. Apesar de expressivo em relação aos analisados até agora, 
outros $64 \%$ de segurados que demandaram o beneficio não obtiveram êxito. Já em 2016, apesar do aumento na demanda pelo benefício, houve queda significativa na taxa de deferimentos, com registro de $11 \%$, ou seja, quase $90 \%$ receberam parecer desfavorável. No ano seguinte, a demanda pelo beneficio cresceu, com aumento para $14 \%$ na taxa de deferimentos, mas a maioria dos requerimentos de aposentadoria foi negada pelo INSS.

Na expressão da região serrana carioca, por meio da Gerência Executiva Petrópolis, identificou-se que em 2015 somente $38 \%$ dos trabalhadores com deficiência tiveram o direito reconhecido, ou seja, a taxa de indeferimento foi superior a $60 \%$. No ano seguinte, apesar da demanda ter duplicado, registramos queda no indice de concessão com $24 \%$ de pareceres favoráveis. Logo,76\% dos segurados tiveram seus pedidos negados junto à autarquia federal. Em 2017, o indice de deferimento permanece decrescente ao registrar apenas $22 \%$, ou seja, quase $80 \%$ de segurados com deficiência obtiveram seus pedidos negados.

Na Gerência Executiva Rio de Janeiro-Centro, em 2015 a taxa de concessão foi de $57 \%$, ou seja, menos da metade dos requerimentos foram indeferidos. Registre-se que se trata da única unidade gerencial do INSS, no periodo analisado, a expressar indice com parecer favorável superior àquele que negou o beneficio. Porém, no ano seguinte, mesmo sendo registrado crescimento na demanda, houve considerável queda na taxa de concessão, que ficou em 33\%. Desse modo, diferentemente da tendência do periodo anterior, expressivos $67 \%$ dos segurados obtiveram negativa institucional. Já em 2017, quando comparado a exercícios passados, segue a dinâmica de aumento apta à análise para reconhecimento inicial do direito. Como no ano anterior, porém, registrou-se queda significativa desse índice, com a estatística de $22 \%$, restringindo o acesso dos demais $78 \%$ de trabalhadores que obtiveram o indeferimento como devolutiva.

Já no âmbito da Gerência Executiva Rio de Janeiro-Norte, os dados são reveladores de uma realidade com taxas de concessão do benefício com decréscimos sucessivos para o período analisado. Em 2015, 72\% dos pedidos foram negados, contrastando com os ínfimos 28\% de trabalhadores com deficiência que conseguiram parecer favorável ao beneficio. No ano seguinte, permanece a lógica de restrição, com apenas 18\% de deferimentos, sendo que a maioria dos segurados, ou seja, expressivos $82 \%$, obtiveram negativa do INSS. Em 2017, a taxa de concessão volta a cair, registrando indice de apenas $16 \%$. Por conseguinte, mais de $80 \%$ de trabalhadores com deficiência ficaram sem o reconhecimento do direito.

Na Gerência Executiva Volta Redonda, em 2015. o índice de deferimento ficou em $24 \%$, portanto, $76 \%$ de trabalhadores não tiveram acesso ao direito. No ano de 2016, seguindo a tendência das demais unidades gerenciais do INSS, houve aumento significativo da demanda, no entanto, manteve-se a lógica restritiva com $74 \%$ dos pedidos indeferidos, embora menor em relação ao ano anterior. Mesmo assim, somente $26 \%$ dos segurados com deficiência tiveram o beneficio concedido. Em 2017, a taxa de deferimentos segue decrescente em relação aos anos anteriores, com $18 \%$ de pareceres favoráveis e manutenção dos elevados índices de benefícios negados pela autarquia federal, que ficou em $82 \%$.

Assim, é possivel depreender desses dados que, para acesso a um mesmo beneficio, neste caso a aposentadoria do trabalhador com deficiência, podem existir compreensões diversas sobre o direito ao beneficio que se materializam na pontuação das avaliações médica e social. Seus critérios, expressos nas 41 atividades dos sete dominios que compõem o instrumental, refletem aspectos restritivos. Isso porque em todas as unidades gerenciais da autarquia federal as taxas de indeferimentos sempre foram superiores às de concessão para o periodo analisado, com exceção daquela do ano de 2015 na Gerência Executiva Rio de Janeiro-Centro, quando o quantitativo de pareceres favoráveis foi superior ao daquele que apontou a tendência de indeferimento.

Nas análises aqui realizadas, esses dados não são expressão do mito que consubstancia dualidades regionais. lanni ajuda a compreender tal realidade: 
Essas descontinuidades são do mesmo tipo e revelam niveis diferentes de integração. São subsistemas que fazem parte intrinseca do todo e representam elementos necessários, ou virtuais, das expansões do todo. As economias de subsistência não são, muitas vezes, senão subsistemas que estiveram integrados de outro modo ao mercado, tendo regredido por causa da dinâmica interna própria desse mesmo mercado. Nesse sentido, são reservas com as quais conta o mercado em suas expansões necessárias. Não se trata de uma integração visivel nas relações entre os núcleos dominantes e os 'bolsões' de subsistência, mas de uma integração estrutural, que escapa às relações de trocas ou comunicações visiveis (IANNI, 1965, p. 77).

Nesse sentido, as desigualdades não devem ser analisadas como problemas de uma determinada região, mas conectada à dinâmica de um país capitalista periférico, que prima pela manutenção dos vínculos de dependência e acirra as desigualdades sociais, econômicas e políticas. Desse modo, é possivel depreender que o desenvolvimento não é avaliado na perspectiva de uma ação histórica com etapas definidas, mas a partir da intrínseca relação entre dependência e (sub)desenvolvimento que integra uma estratégia relacionada ao modo de produção capitalista. Esta, a seu turno, se concretiza de forma desigual e combinada para manutenção da propriedade privada e intensa precarização das condições de trabalho, como lembra oportunamente Prado Jr:

A situação de dependência e subordinação orgânica e funcional da economia brasileira com relação ao conjunto internacional de que participa é um fato que se prende às raizes da formação do país, como já temos repetidas vezes assinalado e é tão óbvio. Economia de exportação, constituida para o fim exclusivo de fornecer gêneros alimentares e matérias primas tropicais aos países e às populações das regiões temperadas da Europa, e mais tarde também da América, ela se organizará e funcionará em ligação intima e estreita dependência do comércio internacional em função do qual se formou e se desenvolveu. Essa é a circunstância principal que tornará o Brasil tão vulnerável à penetração do capital financeiro internacional quando o capitalismo chega a essa fase de seu desenvolvimento. O pais se fará imediata e como que automaticamente, sem resistência alguma, em fácil campo para suas operações (PRADO JR, 2014, p. 116).

Nesse aviltante cenário, conforme fica claro a partir dos dados apresentados, cristaliza-se uma tendência à restrição no acesso ao benefício. Isso expressa o desmantelamento de direitos históricos na sociabilidade capitalista, revelando um intenso movimento de contrarreformas governamentais que, no caso da política pública previdenciária, atinge visceralmente suas prerrogativas, como esclarece Silva:

Associadas à manutenção do consumo em niveis satisfatórios ao capital, ao aquecimento e ao reaquecimento da economia, têm sido as mais valorizadas em detrimento das funções vinculadas à proteção social do trabalhador Isso imprime à previdência social caracteristicas e tendências que a distanciam dos principios da seguridade social e repercutem no acesso aos direitos que viabiliza (SILVA, 2015, 144).

Por essas razões, a mobilização da classe trabalhadora continua sendo imprescindivel para a mudança de natureza do Estado, pois a partir dela diferentes avanços foram obtidos, a exemplo dos direitos políticos. Isto contribuiu significativamente para a expansão e conquista histórica a duras penas dos direitos sociais, principalmente no Brasil, onde o Estado teve sua gênese sob o signo de forte ambiguidade entre liberalismo formal como fundamento e o patrimonialismo como prática no sentido da garantia dos privilégios da classe dominante. Como aponta Fernandes:

\begin{abstract}
Enquanto veículo para a burocratização da dominação patrimonialista e para a realização concomitante da dominação estamental no plano político, tratava-se de um estado nacional organizado para servir aos propósitos econômicos, aos interesses sociais e aos desígnios políticos dos estamentos senhoriais. Enquanto fonte de garantias dos direitos fundamentais do 'cidadão', agência formal de organização política da sociedade quadro legal de integração ou funcionamento da ordem social, tratava-se de um Estado nacional liberal e, nesse sentido, 'democrático' e 'moderno' (FERNANDES, 2006, p. 68).
\end{abstract}

Assim, a partir dos dados analisados que revelam um cenário avesso ao reconhecimento do direito, atualizados pelos expoentes do neoliberalismo, constatamos que os avanços dessas legislações não se concretizam e permanecem apenas no campo formal. Portanto, nessa perversa tessitura da vida social, indagamos, por fim: como contribuir para a materialização desse 
importante direito social do trabalhador com deficiência a partir do proposto pela Convenção da ONU, regulamentado pela LC 142/2013, reiterado pela Lei Brasileira de Inclusão da Pessoa com Deficiência (LBI), com instrumental de avaliação concebido a partir da CIF?

\section{Considerações Finais}

Pensamos que as questões abordadas aqui devam ser amplamente socializadas e discutidas junto aos movimentos sociais das pessoas com deficiência e profissionais envolvidos no processo avaliativo. Naturalmente, não apenas o modelo atual de avaliação médica e funcional deva ser pautado, mas os próprios parâmetros que o norteiam. Estes, como visto, são também extremamente restritivos, o que se potencializa na forma como está expresso nos sistemas operacionais do INSS.

É possivel identificar, ainda, a heterogeneidade de concepções dos profissionais, embora as taxas que negaram o beneficio fossem superior àquelas estatísticas de concessão para o período analisado em todas as unidades gerenciais do INSS. No entanto, quando realizado comparativo entre as gerências da autarquia federal, é possivel observar unidades no Estado do Rio de Janeiro que apresentam indices de indeferimentos bem superiores a outras.

Assim, pensamos que (co)existem, tanto no Serviço Social como na Perícia Médica, concepções que transitam na perspectiva biomédica ou na direção da tese social, o que pode explicar as diferentes taxas de concessão/indeferimento quando utilizado um mesmo instrumental.

Pesquisas futuras devem abordar a formação profissional continuada no âmbito institucional, com programas de treinamentos e conteúdos técnicos. Estes, por sua vez, podem conformar um determinado perfil profissional cerceador de direitos, absorvido pela imediaticidade do cotidiano com metas quantitativas a cumprir, e que concebem isoladamente o indivíduo da estrutura e do contexto sócio-histórico. E isto contribui, como visto, para exponenciar as contradições tão caras às relações sociais capitalistas, principalmente em uma sociabilidade marcada pelo regime de classes, com perpetuação de polarizações.

Nesse sentido, apresenta-se o tenso e histórico terreno da relação entre a acumulação capitalista e as desigualdades sociais. Ele atualiza-se pelo discurso da flexibilização para a tomada de direitos, sob a égide do capital financeiro e uma série de mecanismos de evasão do fundo público arquitetadas pela burguesia rentista sob o aval do Estado.

Assim, as politicas sociais que deveriam atuar como forma de retorno desse orçamento para a classe trabalhadora passam por formatações de modo que não interfiram nos mecanismos de financeirização do capital usurpador dos recursos desse disputado fundo, tendo na desestruturação de direitos as contrarreformas previdenciárias como o fulcro desses desvios.

Para tanto, pensamos ser fundamental o debate sobre a universalização do acesso às politicas públicas, levando em consideração a contextualização histórica de um país periférico e dependente em suas relações econômicas como o Brasil, o que deve ser encampado nas lutas sociais contra o capitalismo. O que está em jogo, afinal, é o destino do escoamento do fundo público. Com isso, conscientes dos limites estruturais nessa sociabilidade paradoxal e desigual, apresenta-se a urgência em articular possibilidades concretas. Elas devem ser construidas a partir de estratégias coletivas, de resistência e enfrentamento ao cenário de intensas contrarreformas que sucumbem conquistas da classe trabalhadora no drama crônico e inextrincável da dialética entre civilização e barbárie.

\section{Referências}

BRASIL. Constituição da República Federativa do Brasil. Brasilia: Gráfica do Senado Federal, 1988.

BRASIL. Convenção sobre os direitos das pessoas com deficiência. 4. ed. Brasília: Secretaria de Direitos Humanos, 2012. 100p

BRASIL. Lei Complementar $n^{\circ} 142$, de 8 de maio de 2013. Regulamenta o $₹ 1^{\circ}$ do art. 201 da Constituição Federal, no tocante à aposentadoria da pessoa com deficiência segurada do Regime Geral de Previdência Social - RGPS Disponivel em: http://www.planalto.gov.br/ccivil_03/ leis/lcp/lcp142.htm. Acesso em: 03 mar. 2019. 
BRASILIA (Distrito Federal). Portaria Interministerial AGU/ MPS/SEDH/MP n' 01, de 27 de janeiro de 2014. Aprova o instrumento destinado à avaliação do segurado da Previdência Social e à identificação dos graus de deficiência, bem como define impedimento de longo prazo, para os efeitos do Decreto $n^{\circ} 3.048$, de 6 de maio de 1999. Brasília, 2014.

CENSO DEMOGRÁFICO 2010. Caracteristicas gerais da população, religião e pessoas com deficiência. Rio de Janeiro: IBGE, 2012. Disponivel em: ftp://ftp.ibge.gov. br/Censos/Censo_Demografico_2010/Caracteristicas_Gerais_Religiao_Deficiencia/caracteristicas_religiao_deficiencia.pdf. Acesso em: 08 mar. 2019

DINIZ, Débora. O que é deficiência? São Paulo: Brasiliense, 2012.

FRANÇA, Thiago Henrique de Pinho Marques. Deficiência e pobreza no Brasil: a relevância do trabalho das pessoas com deficiência. 2014. 336f. Tese (Doutorado em Sociologia) - Faculdade de Economia da UC. Universidade de Coimbra, Coimbra, 2014

FRANZOI, Ana Cristina et al. Etapas da elaboração do Instrumento de Classificação do Grau de Funcionalidade de Pessoas com Deficiência para Cidadãos Brasileiros: Índice de Funcionalidade Brasileiro - IF-Br. Revista Acta Fisiátrica, São Paulo, USP, v. 20, n. 3, pp. 164-178, 2019.

FERNANDES, Florestan. A revolução burguesa no brasil: ensaio de interpretação sociológica. Rio de Janeiro: Biblioteca Azul, 2006

FONSECA, Ricardo Tadeu Marques da. A ONU e o seu conceito revolucionário de pessoa com deficiência. 2008. Disponivel em: http://styx.nied.unicamp.br/todosnos/ noticias/a-onu-e-o-seu-conceito-revolucionario-de-pessoa-com-deficiencia/. Acesso em: o9 mar. 2019.

HILLESHEIM, Jaime. Conciliação trabalhista: ofensiva sobre os direitos dos trabalhadores na periferia do capitalismo. 2015. 695f. Tese (Doutorado em Serviço Social) - Centro Socioeconômico da UFSC. Universidade Federal de Santa Catarina, Florianópolis, 2015.

MANDEL, Ernest. Marxismo revolucionário atual. Rio de Janeiro: Zahar, 1981.

MARX, Karl. O capital. 12. ed. Tradução: Reginaldo Sant'Anna. Rio de Janeiro: Bertrand Brasil S. A., 1988. Livro 1. Volume I.

IANNI, Octavio (org.). Politica e revolução social no Brasil. Rio de Janeiro: Civilização Brasileira, 1965.

PRADO JR., Caio. A revolução brasileira: a questão agrária no Brasil. São Paulo: Companhia das Letras, 2014.

RIBERTO, Marcelo et al. Validação da Versão Brasileira da Medida de Independência Funcional. Revista Acta Fisiátrica, São Paulo, USP, v. 11, n. 2, pp. 72-76, 2004.

SILVA, Maria Lúcia Lopes da. Trabalho e previdência social no Brasil no contexto de crise do capital. O social em questão. Rio de Janeiro, PUC-RJ, n. 34, pp. 137-16o, jul./dez. 2015. Disponivel em: http://osocialemquestao. ser.puc-rio.br/media/OSQ_34_6_Silva.pdf. Acesso em: 14 mar. 2019.

\section{Alano do Carmo Macedo}

Assistente Social do INSS, lotado na Gerência Executiva Rio de Janeiro - Centro.

Doutor em Serviço Social pela Universidade Federal de Santa Catarina (UFSC).

\section{Correspondência}

Gerência Executiva Rio de Janeiro - Centro

Rua Pedro Lessa, 36 - Centro

Rio de Janeiro, RJ, BR

CEP: 20030-015 